\title{
El significado político del desarrollo y la búsqueda de alternativas
}

\section{Introducción}

No solamente es posible analizar la continua existencia de una crisis del desarrollo en la periferia de la economía-mundo capitalista -una crisis que se ha constituido en crónica en muchas partes de la periferia y que ha dado como resultado que el concepto mismo de "crisis" sea cuestionado-, sino también se puede llamar la atención acerca de una crisis en la teoría del desarrollo y en los intentos de representar el significado mismo de la noción de desarrrollo. En especial, las interpretaciones críticas han venido experimentando un período de replanteamientos; ideas de un llamado impasse en el marco de problemas teóricos y las preocupaciones sobre el rompimiento de un relativo consenso, reflejan un ánimo de dudas y, en algunos casos, un penetrante sentimiento de desencanto. Mientras tanto, bajo el signo de un "impulso universal hacia la abundancia" (Connolly, 1991), los imperativos del neo-liberalismo continúan su marcha por medio de nuevos oleajes de modernización capitalista. En este artículo se discuten los principales referentes y significados en los que la noción de desarrollo se articula y dan forma a su discurso. Al mismo tiempo, se plantea que la contribución de la crítica cultural es indispensable para configurar un discurso alternativo que, en la actualidad, pueda ofrecer resistencia a la ofensiva de la globalización neo-liberal.

\section{Desarrollo en tiempos de desencanto}

Para los pobres, en muchos países del sur, la década de los ochenta se caracterizó como la "década perdida (Banco Mundial, 1990, p. iii). En América Latina y África, la declinación del Producto Interno Bruto per cápita, el crecimiento del peso de la deuda, las tendencias negativas en el nivel de los salarios reales, el crecimiento en el desempleo y subempleo urbano, el aumento en las desigualdades económicas y la urbanización, así como la feminización de la pobreza, son solamente algunos de los aspectos mejor conocidos de la crisis socioeconómica (Ghai y Hewitt de Alcántara, 1990). Esta lista parcial podría todavía 
aumentarse; en América Latina, por ejemplo, se pueden agregar los problemas de las drogas, el SIDA, la emigración y la intensificación de las nuevas formas de violencia; en las innumerables regiones del sur, la degradación y desvastación ambiental se agudizan; y en una creciente cantidad de áreas, las cicatrices psicológicas de la pobreza y la destitución continúan erosionando el potencial de la emancipación humana. Orientado dentro de cierta tradición, se puede incluso sugerir que estamos viviendo el "fin del desarrollo". Pero, ies realmente cierta esta afirmación? ¿Qué significados podemos atribuir al "desarrollo" en los noventa? Antes de discutir estas y otras interrogantes, a continuación se examinan algunos aspectos del dominante discurso neo-liberal sobre el desarrollo.

Los ochenta fueron la década de los "ajustes estructurales", de la imposición de una nueva ronda de "disciplina financiera" y del "alineamiento del estado" (Fishlow, 1990); fue el período de la retirada del keynesianismo y la entrada en la palestra de un "novedoso" paradigma construido sobre la base del discurso neo-clásico. Los contenidos del paquete de "ajuste estructural" son bien conocidos; se encuentra, inter alia, devaluación, aumento en los precios de los productos y una reducción en los salarios, congelamiento de los mismos, eliminación de subsidios y privatización. Los conceptos estratégicos son: cortar, diferenciar, despedir y disciplinar. No obstante, el proceso de ajuste va más allá de ser un ejercicio puramente económico. Para ilustrar lo anterior, se puede hacer referencia al caso salvadoreño.

En 1989, el recientemente electo gobiemo de Alfredo Cristiani declaró la necesidad de llevar a cabo una serie de reformas económicas indispensables para la supervivencia del país. Estas reformas eran parte de un programa, en gran medidad elaborado por economistas chilenos vinculados con la Fundación Salvadoreña para el Desarrollo Económico y Social (FUSADES), think tank de la clase empresarial local, que exigía un cambio de rumbo de la economía del país. Este programa se fundaba en la creencia de que la causa de la crisis era el Estado y que su solución era el mercado. Con el control del gobierno y con el apoyo parlamentario de su partido, la admistración Cristiani se lanzó a un agresivo y no muy transparente plan de privatización de la banca estatizada y de otras empresas estatales, de eliminación de los obstáculos al comercio exterior y de la inversión extranjera, eliminación de subsidios, reducción de personal del sector público, etcétera. Los elementos claves del discurso gubernamental fueron el asociar la idea de salvar al país con la necesidad de la acumulación privada, de vincular la "necesidad racional", de "administrar los recursos escasos" con las políticas monetaristas y fortalecer el imperativo de la competitividad en el contexto de un mercado "auto regulado". Este discurso transformaba apariencia en realidad. Así, simulaba la idea de "logro económico" que tenía como base el control de la inflación, pero ignorando la vital incorporación de los "pobredólares", y desimulaba los costos sociales reales a través de proyectar una imagen de aceptación social de las políticas estatales. 
Analizando otras regiones, pero señalando elementos constituyentes del discurso y de la práctica neo-liberal, Broad (1990) analizó el impacto de las políticas del Fondo Monetario Internacional (FMI) y del Banco Mundial (BM), criticando la ecuación ortodoxa crecimiento-desarrollo. En una exploración muy amplia, Biersteker (1990) argumentó que las recetas del FMI y del Banco Mundial socavan las bases fiscales del Estado periférico, y en el proceso pone en peligro su legitimidad a largo plazo. Finalmente, Prayer (1991) examinó los aspectos relacionados con la política de la deuda, enfatizando el hecho que desde 1982 el Tercer Mundo ha sido un exportador neto de divisas fuertes hacia los países avanzados $^{2}$.

Los ochenta comenzaron con el hecho de que el Banco Mundial acentuaba la centralidad del crecimiento económico. Realmente se argumentó, por ejemplo, que existía suficiente evidencia indicando que "el crecimiento económico por lo general contribuye a aliviar la pobreza" y que, en un sentido más general, "el desarrollo humano depende del crecimiento económico proporcionando los recursos para la expansión del empleo productivo y los servicios básicos" (Banco Mundial, 1981, pp. 67, 69). Para los comienzos de los noventa, se sugería que el desarrollo solo podría ser fructífero si era "amigable al mercado". Después de una década de "ajuste estructural", el Banco Mundial percibió que la función más apropiada para el gobierno era la de apoyar más que suplantar los mercados competitivos (Banco Mundial, 1991, p. 11); esta percepción es todavía uno de los elementos centrales del discurso oficial del Banco. El papel es definido en relación con un número de funciones. Los gobiemos deben invertir en educación, salud, nutrición, planeamiento familiar y programas para aliviar la pobreza; además, invertir en infraestructura (por ejemplo, obras sociales, físicas, administrativas, de seguridad y legales), movilizar recursos para los gastos de las finanzas públicas, intervenir para proteger el medio ambiente y proporcionar un marco de estabilidad macroeconómica. Estas son consideradas funciones claves de los gobiernos.

Es por supuesto sintomático de la ortodoxia actual el de brindarle mucha atención y consideración analítica al replanteamiento del Estado y al refinamiento de los preceptos de privatización y desregulación. La cuestión es que dentro del discurso oficial del Banco Mundial, del FMI y de una amplia gama de organizaciones internacionales, raramente se encuentra una discusión acerca de la necesidad de un replanteamiento del papel del sector privado; en otras palabras, mercado, libre comercio e inversión, funcionamiento de la empresa capitalista, política de acumulación y así por el estilo son referentes que son protegidos de cualquier crítica cuestionadora. Además, no es sólo la ausencia de una consideración crítica del sistema económico la que necesita ser mencionda, sino también la naturaleza fundamental de la filosofía política que gobierna la conceptualización de lo económico; es decir presentar abiertamente, la que es, a menudo, una escondida pero crucial definición del individuo y del "desarrollo 
humano". Por considerarlo de singular importancia se rastrearán algunos aspectos de la continuidad del discurso neo-liberal contemporáneo con respecto al desarrollo.

En el contexto latinoamericano, Nun (1991) nos invita a prestar atención a la tendencia de que versiones idealizadas de la modernización se diseminen a través de todo el continente. En este sentido, la continuidad del proceso de modernización tiende a ser obscurecido. Por ejemplo, hace más de 25 años Sunkel se refería a la realidad combinada de una integración transnacional con una desintegración nacional, y el mismo Nun se refirió a la idea de una "masa marginal", enfatizando la naturaleza particular del desarrollo de un relativo excedente de población en las sociedades periféricas. En la actualidad, sin embargo, se nos presenta lo que Nun apropiadamente describe como "discontinuidades en el imaginario", como si la región no haya experimentado ninguna penetración capitalista, como si sus economías nunca hubiesen estado abiertas al mercado mundial, como si a principios de los sesenta la doctrina de la modemización no hubiese existido. Además, también existe la tendencia a invertir la relación con la democracia; ahora la democratización política es vista como un paso obligatorio y preliminar para alcanzar la modemización económica y social. Pero qué tan significativa, o incluso segura, es esa democracia, cuando la nueva oleada de modemización capitalista es acompañada por una privatización a gran escala, y por un énfasis en el abandono de las funciones económicas y sociales del estado periférico - esto en sociedades ya severamente corroídas por pasadas ofensivas de modemización capitalista-.

La conexión histórica en este pasaje nos lleva a retroceder a los cincuenta y comienzo de los sesenta, en ese período fue cuando la primera oleada de la teoría de la modemización dio credibilidad discursiva a la expansión de las inversiones de Estados Unidos, y todavía más importante a la difusión del poder geo-político estadounidense ${ }^{3}$. Sin embargo, la posible genealogía de las nociones actuales de auto-regulación, de la santicidad de la propiedad privada, de la superioridad cultural de occidente, de la minimización de la función socioeconómica del Estado, de la celebración del individuo como poseedor y de la centralidad de la capacidad de adquirir, nos puede hacer retroceder aún más en el tiempo.

Escribiendo a comienzos de los cuarenta, Laski (1943) indicó que algunos encontrarían la salvación en la famosa máxima ne pas trop gouverner; permitan al gobiemo restaurar una vez más la libertad de empresa para los hombres de negocio, y podríamos entrar así en una nueva era de creatividad en donde la guerra y la inseguridad se abolirían. Detrás de esta máxima se encuentran una serie de supuestos que Laski ordena de la siguiente manera: "que la propiedad privada en los instrumentos de producción es sagrada, que cualquier cosa hecha por alguna institución del gobiemo debe ser de inferior calidad que si fuera intentada por la empresa privada, que el poder de hacer las leyes opera en el 
interés común, que cada hombre conoce mejor su propio interés y está en una mejor posición de hacerlo avanzar" (Laski, 1943, p. 13). Para Laski, estos supuestos no solamente eran insostenibles, sino que, además, echando una mirada al pasado, sugieren que si bien los hombres de negocios tuvieron un "siglo de espacio en el cual probaron la validez social de su filosofía... al final, podría escribirse, por todas sus tempranas conquistas, sólo como fue un siniestro fracaso que esclavizó todos los continentes en función de los intereses rapaces del beneficio privado" (op. cit., 15)4.

Alrededor de los mismos años que Laski estaba elaborando sus reflexiones sobre el mundo durante un período de guerra, Polanyi propuso una interpretación similar con respecto a la noción de un mercado auto-regulado. En esos años, Polanyi argumentó en un incisivo texto que sobrevive el peso del tiempo, que la "verdadera crítica de la sociedad de mercado es no que esté basada en la economía sino que su economía está basada en el auto-interés" (Polanyi, 1957, p. 249). Los pensadores del siglo XIX asumían que el hombre, en su actividad económica, perseguía la ganancia y nada podría ser más normal que un sistema económico consistente de mercados; además, la meta de todo progreso era percibida como el desarrollo de una sociedad basada en el mercado. Sin embargo, como Polanyi nos recuerda, contrario al mito de la emergencia natural de un mercado auto-regulado, el mercado fue el resultado de una "consciente y a menudo violenta intervención de parte del gobiemo que impuso la organización del mercado a la sociedad para fines no económicos" (op. cit., 250).

Las relaciones basadas en el mercado no deben ser vistas como separadas de las concepciones del individuo. Transportándonos unos siglos atrás, resulta claro que en los trabajos de Hobbes y Locke, y especialmente en los del primero, se pueden ubicar las raíces de la mayoría del pensamiento moderno acerca de las relaciones entre el mercado y el individuo. En Hobbes y Locke, la imagen del individuo es creada a la imagen del hombre del mercado. Si la sociedad es una serie de relaciones entre propietarios, la sociedad política es, en consecuencia, un instrumento contractual para la protección de los propietarios y de la regulación ordenada de sus relaciones. El académico canadiense Macpherson (1988), en su fascinante estudio sobre las raíces de la teoría democrático-liberal, convincentemente argumenta que el individualismo original del siglo XVII tenía una cualidad esencialmente posesiva. Esta cualidad posesiva se encuentra en su concepción del individuo como básicamente propietario de su persona o de sus capacidades y, por lo tanto, sin ningún tipo de deuda con la sociedad. Como lo expresara Macpherson (1988, p. 3): "la esencia humana es libre de la dependencia de la voluntad de otros, y la libertad es una función de posesión". En la visión de Hobbes, la sociedad es percibida como una serie de relaciones competitivas entre individuos naturalmente disociados e independientemente auto-motivados, sin un orden natural de subordinación. 
La centralidad del individuo posesivo, de la santicidad de la propiedad y de la soberanía del mercado, continuó a través del siglo XIX y más allá, por supuesto no sip oposición, ni sin, especialmente en el siglo XX, una mayor modificación con, por ejemplo, el desarrollo de un vigoroso papel socio-económico del Estado. Hirschman (1981), en su elocuente examen sobre los argumentos políticos del capitalismo antes de su triunfo, indica los modos en los que los intereses, el hacer dinero, la acumulación y la creación de riqueza fueron vistas como un camino saludable e innocuo alejado de lo potencialmente desastrozas pasiones auto-destructivas y violentas de la naturaleza humana. El deseo de la ganancia y del auto-mejoramiento del individuo fueron conferidos con una cualidad de virtuosidad que Hirschman traza a través de una amplia variedad de escritores que van desde Smith hasta Keynes.

Pero la asociación de la búsqueda del interés material con la racionalidad y la virtud, y la separación representada de dicha búsqueda de la osadía de la pasión, no estuvo ausente de críticas, como se demuestra en los trabajos de Ferguson y Tocqueville. Obviamente, sin embargo, la idea de que los hombres en la búsqueda de sus intereses serían por siempre inofensivos fue abandonada cuando, como Hirschman lo señala (1981, p. 126): "la realidad del desarrollo capitalista se encontraba en plena marcha". En la medida en que la expansión de la acumulación de capital, durante los siglos XIX y XX, desarraigaba a millones de personas, generaba un aumento en la polarización social y creaba un desempleo a gran escala, quedó claro que quienes estaban atrapados en estas transformaciones violentas podrían "en ocasiones convertirse en apasionados-apasionadamente coléricos, temerosos y resentidos" (Hirschman, ibíd.).

Si el espíritu dominante de nuestra época reviste el mercado con el signo de lo sagrado, y proyecta la imagen del individuo embebido en el imperativo de la posesión, no debemos asumir que este espíritu no tiene historia. El individualismo posesivo que Macpherson localiza en el siglo XVII ciertamente no se ha evaporado. Castoriadis, en una réplica a los problemas sobre la democracia y la política, argumenta que el impulso principal de la sociedad contemporánea es la maximización de la producción y del consumo. Esta maximización se ha convertido en la casi exclusiva significación del imaginario de la sociedad de fines del siglo XX y pareciera ser que lo será a principios del próximo. Para Castoriadis (1990, p. 137): "en tanto se mantenga la pasión exclusiva del individuo moderno, no cabe ninguna duda del lento avance que experimentarán los contenidos democráticos y las libertades"; y continúa "la democracia es imposible sin una pasión democrática; una pasión por la libertad de cada uno y de todos, una pasión porque los problemas comunes se transformen... en los problemas personales de cada uno".

Castoriadis ve la sociedad moderna como caracterizada por la emergencia de un tipo de individuo centrado en el consumo, apático sobre los problemas públi- 
cos y cínico en relación con la política. Este autor enlaza esta actividad con el proceso de privatización y el desarrollo de la despolitización de lo social, de la creciente apatía y conformidad. Su concepción sobre la democracia está relacionada con la reflexión política, la cual la concibe como grandemente ausente del mundo contemporáneo. Siguiendo a Castoriadis se puede afirmar que en el mundo contemporáneo, el liberalismo individual presupone un modelo del individuo normal o racional contra el cual la conducta y realidad intema de cada uno es medida y evaluada. En esta clase de teorización la compleja política de la identidad y subjetividad no es tomada en cuenta; en su lugar existe una fuerte tendencia de apoyo a una "política de individualización normal" (Connolly, 1991, p. 75).

En general, el argumento principal sustentado en la presente discusión es: primero, que la ortodoxia actual del neo-liberalismo con su ensamblaje normativo de mercado, democracia e individuo presenta una continuidad que necesita ser analizada permanentemente ${ }^{5}$; segundo, que cuando se desarrolle una crítica a las políticas de ajuste estructural, del monetarismo y, en términos más generales, del discurso neo-liberal, es esencial recordar que la constitución teórica de lo económico también define una concepción del individuo; y tercero, que esta concepción del inviduo pósesivo está encapsulada en una filosofía política que aspira a ser universal y permanente; la creencia de Fukuyama (1989) en la "universalización de la democracia liberal-occidental como la forma final de gobierno humano" representa un ejemplo de tal proyección.

Estos tres puntos están interrelacionados y conectados a un planteamiento que necesita una breve introducción. La actual ortodoxia sobre el desarrollo lleva consigo una interpretación particular de occidente y del resto del mundo, que es clave en la construcción de su significado. Esto es lo que Mohanty (1988), en la esfera de los estudios feministas, ha apropiadamente calificado como un universalismo etnocéntrico, que recibe su más profunda y penetrante expresión en el campo de la teoría convencional del desarrollo.

Se recordará que uno de los principales argumentos de la perspectiva de la dependencia, fue cuestionar los dos pilares principales de la teoría de la modernización. Primero, la noción de que el Tercer Mundo no tenía una historia significativa previamente a su "descubrimiento" e inscripción dentro de la lógica de la expansión europea, fue efectivamente desacreditada. Segundo, la contención de que las relaciones entre el Primer y el Tercer Mundo habían sido beneficiosas para el Tercero fue invertida: en contraposición a la doctrina convencional, frecuentemente los dependentistas argumentaron que la periferia sufrió de estas relaciones; que las mismas crearon el subdesarrollo, la extracción del excedente y le dieron vida al síndrome dominación/dependencia. De esta tesis se desprendió la idea de que el desarrollo podría ser efectivo sólo mediante el rompimiento radical y revolucionario con el capitalismo internacional (Alfaro, 1990). Estos dos componentes formaron el principal objeto de la crítica, pero hizo falta un 
tercer componente. Lo que se necesitó y todavía se necesita, probablemente hoy más que nunca, es la deconstrucción del edificio imaginario llamado Mundo Occidental.

Un enfoque de tomarse en consideración es aquel que percibe al Primer Mundo como "el otro"; el que nos invita a pensar en sus peculiaridades, a investigar lo "salvaje" y "primitivo" en lo "sofisticado" y lo "modemo"; en perturbar y subvertir la sedimentación convencional del significado que brinda a occidente su normalidad aparente y su certeza de superioridad. En la evaluación de las sociedades, se puede pensar en una serie de factores que podrían permitir a El Salvador o Guinea Ecuatorial encontrarse en un nivel de desarrollo superior a Estados Unidos o España si se comparan las tasas elevadas de crímenes violentos, los niveles en el abuso de las drogas, el tratamiento de los ancianos, los valores de la comunidad, etcétera. Desde el advenimiento del esclavismo, a través de la "innovación modemizante" del colonialismo al barbarismo del fascismo y la maquinaria de la violencia de un asesino en serie que puede fabricar piezas de muebles de los restos de sus víctimas, el lado obscuro de occidente se ha convertido en objeto de estudio. Dicho proyecto no tendría como meta una política de simple reversión, donde, parafraseando a Stuart Hall, se reemplazaría al sujeto social blanco y malo (Primer Mundo) por el, esencialmente, sujeto negro y bueno (Tercer Mundo). Más bien se necesita enfatizar en la compleja diversidad y heterogeneidad de la periferia con su rica pluralidad de experiencias políticas como altemativa opuesta a la visión etnocéntrica y estereotipada de la realidad del Tercer Mundo.

Cuando un intelectual como Fukuyama $(1989$, p. 9) llama la atención sobre el "igualitarismo de la América modema", lo cual es visto como la representación de "el logro esencial de la sociedad sin clases prevista por Marx", incluso el lector menos crítico dudará de la certeza de tal afirmación. Si bien se admite por parte de este intelectual del establishment que existe una desigualdad económica, y que la brecha entre ricos y pobres ha crecido en los años recientes, todavía se mantiene que los fundamentos de la estructura social y legal de Estados Unidos es "fundamentalmente igualitaria y moderadamente distribucionista" por naturaleza, así que los orígenes de la desigualdad económica hay que buscarla en el legado de los tiempos pre-modernos, al igual que las condiciones que dieron origen a la "pobreza de los negros".

Al mismo tiempo, presentando un argumento a la hegeliana, al lector se le informa que cuando se considere la "herencia ideológica común de la humanidad... importa muy poco que extraños pensamientos se le ocurran a la gente de Albania o Burkina Faso (ibid.); en cualquier caso, la "vasta mayoría del Tercer Mundo permanece estancado históricamente", en vista de que están todavía buscando su autencidad mal orientada, en lugar de embarcarse en el universalismo del proyecto democrático-liberal. 
De la idea de tal infortunado destino, de matenerse atascado en la historia, atrapado en una atrasada autencidad, comenta un autor tercermundista, pareciera entonces deducirse que "unirse al oeste en la búsqueda del progreso es un imperativo, un avance, una condición casi necesaria para el ser humano" (Du Bois, 1991). En un estilo similar, las nociones tradicionales de subdesarrollo o la situación de "la senda al desarrollo", captura un sentido de ausencia, y una ausencia, como Du Bois (1991, p. 2) lo observa, que "se yergue en alivio contra el telón de fondo de una sociedad occidental completa". Pero esta idea de la terminación, de estar en una situación que ya es "desarrollada", que mantiene fuera a aquellos que tienen la voluntad de "desarrollar" la imagen de su futuro potencial, es una idea basada en una idealización etnocéntrica de la sociedad modema.

Finalmente, en este sentido, y recordando el segundo componente de la crítica radical de la dependencia, la celebración de una cierta versión del proyecto democrático-liberal fracasa, al no tomar en cuenta la larga historia de la penetración capitalista-occidental y la consecuente subordinación de las sociedades periféricas a esta lógica.

Los intentos de disciplinar al Tercer Mundo, de vigilar "el proceso de desarrollo" y de castigar aquellos gobiernos o movimientos que se oponen a la voluntad del poder global; todos estos modos de intervención y sujeción han dado continuamente origen a elementos de resistencia, rebelión y revolución. ¿Cómo, en la antesala de un nuevo milenio, es posible abordar los problemas del desarrollo y las prácticas que éste genera? ¿Existe la posibilidad de salir del presente "impasse"?

\section{Hacia un análisis cultural del desarrollo}

Desde la perspectiva del discurso convencional del desarrollo, es extremadamente difícil concebir otras visiones de mundo que sean igual de valederas a las existentes, o de otros modos de vida que tengan igual valor o que proporcionen las mismas satisfacciones. Sin embargo, si el desarrollo es concebido principalmente en términos de la lucha por el control de los destinos, entonces el desarrollo de la mayoría de los habitantes del planeta será fundamentalmente un acumulación de formas, mediante las cuales resisten, manipulan y se adaptan a las fuerzas que actuan sobre ellos. Es esta lucha por la hegemonía y contra-hegemonía en donde el "desarrollo" se ha convertido en un sitio disputado, esto es el terreno del análisis cultural. En consecuencia, para enfocar el desarrollo desde la perspectiva del análisis cultural, es necesario interrogarse acerca del significado del desarrollo, acerca de la producción de conocimientos, acerca de quién decide y quién tiene la fuerza de los recursos, coercitivos o persuasivos, para hacer de su versión de la realidad algo permanente. 
En la mayoría de escritos acerca de la cultura se tiende a considerarla como una cosa, o una colección de cosas. Es también considerada como un espacio o una "dimerísión del desarrollo", de alguna manera distinta de los procesos sociales, económicos y políticos. Para otros, la cultura es todo. "La cultura significa... cada aspecto de la vida; know how, conocimiento técnico, costumbres o comida y vestido, religión, mentalidad, valores, lenguaje, símbolos, comportamiento socio-político y económico, métodos locales de tomar decisiones y ejercer el poder, métodos de producción y relaciones económicas" (Verhelst, 1990, p. 17). Una sociedad no está solamente constituida por cosas materiales, como el territorio que ocupa, los objetos que se elaboran y utilizan, por las acciones que se realizan, sino, sobre todo, por la idea que tiene de sí misma - su imaginario social (Maffesoli, 1993, p. 5)- El imaginario social está constituido por una serie de mitos, imágenes, leyendas, rituales e íconos que tienen un contenido emocional, intelectual y moral que desempeñan una función central en el mantenimiento e impulso de las energías de la vida social (Horne, 1994). En tal sentido, Rist (1990) habla del mito del desarrollo como un motor simbólico que impulsa los procesos socioeconómicos de una formación social concreta. Estos elementos constituyentes del imaginario social, a pesar de que no son reductibles a lo material, son, sin embargo, social e históricamente construidos y pueden ser analizados de esa manera.

Lo valioso del concepto de cultura es que conduce nuestras percepciones hacia la dimensión cognitiva de la experiencia; hacia un análisis de cómo el conocimiento, el significado y la comprensión son construidos y comunicados. También nos lleva a prestar atención a las experiencias y preocupaciones emocionales y morales; a la "estructura de los sentimientos" que tiene tanto aspectos individuales como colectivos; y hacia los modos en los que los impulsos morales y su modos de entendimiento son construidos. Estas son las preocupaciones que no han recibido una atención adecuada en los estudios sobre el desarrollo, si bien estas han sido la preocupación central de las necesidades humanas y de los discursos sobre los derechos humanos. El feminismo académico ha contribuido notablemente en la investigación sobre el desarrollo, al llevar a la discusión las preocupaciones sobre el cuerpo, las emociones y lo "subjetivo". El análisis cultural gira en torno al análisis crítico de los procesos de construcción y de construcción de significados.

La premisa fundamental del análisis cultural es la realidad como una construcción social, lo que nos obliga a considerarla no como algo natural o autoevidente. Asimismo, la realidad es también múltiple. Existen diversas versiones que convergen y conflictúan en una gran cantidad de maneras. Así, la realidad no es sólo construida sino cuestionada y negociada. Algunas ideas, significados y modos de percibir predominan y otros se encuentran sumergidos o marginados. De la misma manera que se habla de que centros económicos y políticos están marginando o periferizando otras unidades sociales, lo mismo se puede 
decir sobre formas de percepción dominantes y subordinadas. Entonces, la tarea es definir los desafios metodológicos planteados por el análisis cultural, un desafío que incluye la articulación de enfoques multidimensionales al estudio del desarrollo, que combinen el análisis cultural con las herramientas de la economía política. Al mismo tiempo, es preciso no caer en los terrenos del "culturalismo"; es decir, en la idea de que existen elementos constantes y transhistóricos peculiares a cada una de las culturas humanas y que todas estas culturas son de “igual valor". Visto así, este planteamiento puede ser acomodado perfectamente por la utopía neo-liberal.

El análisis cultural brinda una atención particular a la producción de conocimiento y a la construcción de significados. Desde esta perspectiva, desarrollo, como en general es construido, es la imposición de una noción particular del destino de la sociedad a escala global. Es la imposición de significados y valores externamente construidos en relación con una diversidad de grupos sociales y territorios. "Desarrollo" se plantea como una forma de conocimiento globalizado y pretende una validez universal que margina formas locales de conocimiento. Pero la hegemonía de la noción de desarrollo, en su forma actual, está siendo cuestionada cada vez más por formas subalternas de conocimiento y por movimientos sociales contra-hegemónicos, cuyos intereses y metas son diferentes al de aquellos agentes e instituciones que, en la actualidad, pretenden poseer el derecho de definirlo. Es importante, por lo tanto, encontrar modos de incorporar esas voces y puntos de vista al discurso del desarrollo.

Para ilustrar lo anterior se puede tomar un referente de moda: el desarrollo sostenible. Probablemente en la actualidad en los círculos políticos e institucionales la discusión y preeminencia de la noción de "desarrollo sostenible" se haya convertido en uno de los componentes claves de su discurso del desarrollo. Desde la perspectiva del análisis cultural se puede avanzar en su crítica. En su estructuración, códigos "sostenibles" de conducta son adheridos a la noción del desarrollo. Lo que convierte desarrollo en desarrollo sostenible es el principio que "las necesidades de las presentes generaciones deben satisfacerse sin comprometer la capacidad de las futuras generaciones para lograrlo". Pero esto es, en efecto, la esencia de estilos de vida tradicionales que son intrínsicamente conscientes del futuro: el engrandecimiento de la vida tradicional ha sido siempre la preservación de los recursos para la posteridad. En tal caso, qué necesidad tienen esas comunidades de desarrollo sostenible; simplemente lo que debe hacerse es permitir a estos estilos de vida tradicionales continuar, ajustándose a los cambios de acuerdo con sus propios criterios de prosperidad. Sin embargo, hacer esto sería actuar contra el principio cardinal del desarrollo; es decir, el occidente es el que debe dictar lo que el "otro" (no-occidental) debe hacer y cómo debe hacerlo, incluso si el "otro" ha estado haciendo lo que occidente le ha exigido hacer por siglos. 
El reto planteado por la crítica cultural a los estudios sobre el desarrollo implica un replanteamineto de las bases epistemológicas de toda la teoría social. Este replanteamineto permitiría producir estudios etnográficos de las instituciones gubernamentales, empresas multinacionales y de organizaciones sociales a un nivel macro, esos sitios a los que, en los estudios sobre el desarrollo, se hace referencia como los que se encuentran a un nivel global o del sistema mundial. Ahora bien, ipodemos producir etnografías del Fondo Monetario Internacional, Banco Mundial, organismos de cooperación, agencias de ayuda y centros de "investigaciones para el desarrollo"? ¿Cuál es la imagen que ellos tienen de "desarrollo", "subdesarrollo", "programas de desarrollo", "estudios de desarrollo"? ¿Cuáles son los discursos y paradigmas dominantes y los discursos emergentes o "alternativos"? ¿Cuáles son los mitos, leyendas, íconos y rituales que dan forma a la producción social del "desarrollo"? Para darle una respuesta positiva a éstas y otras interrogantes es necesario articular un discurso que enfatize en el análisis de los procescs culturales contenidos en el desarrollo y en las estrategias culturales de quienes están empeñados en resistirlos.

El discurso alternativo del desarrollo tiene que tomar en cuenta las culturas locales en su más amplio sentido y proporcionar espacio en su construcción a las iniciativas de los sectores subalternos. Se deben reconocer las complejidades de la "cultura" como sujeto y asegurar que dichas complejidades sean reconocidas, representadas y respetadas. Por otra parte, las opciones de desarrollo deben incluir una comprensión integrada de las culturas particulares de los pueblos; es decir, un reconocimiento de la importancia social, histórica y espiritual de sus prácticas cotidianas y de sus experiencias colectivas.

\section{Referencias bibliográficas}

Alfaro, S.O., Theories of Development and Social Change, Tesis de Maestría en Sociología, University of Regina, Regina, Canadá, 1990.

Banco Mundial, Informe del Desarrollo del Mundo, Nueva York, 1981, 1990, 1991.

Biersteker, T.J., "Reducing the Role of the State in the Economy: A Conceptual Explanation of IMF and World Bank Prescriptions", International Studies Quarterly 34, 1990, pp. 477-92.

Broad, R., Unequal Alliance-The World Bank, The International Monetary Fund and the Philippines, Berkeley and London, University of California Press, 1990.

Castoriadis, C., "Does the Idea of Revolution Still Make Sense? -an interview with Cornelius Castoriadis", Thesis Eleven 26, 1990, pp. 123-38.

Connolly, W.E., Identity/Difference-Democratic Negotiations of Political Paradox, Ithaca, Cornell University Press, 1991.

DuBois, M., "The Governance of the Third World: A Foucauldian Perspective in Power Relations in Development", Alternatives, Vol. 6, 1, 1991, pp. 1-30.

Fishlow, A., "Streamlining the State", Hemisfile, enero, 1990, pp. 1-2.

Fukuyama, F., "The End of History", The National Interest, 1989, pp. 3-18. 
Ghai, D. y Hewit de Alcántara, C., "The Crisis of the 1980s in Subsaharan Africa, Latin America and the Caribbean", Development and Change, Vol. 21, 3, julio, 1990, pp. 389-426.

Hirschman, A. O. The Passions and the Interests-Political Arguments for Capitalism before its Triumph, Princeton, Princenton University Press, 1981.

Horne, D., The Public Culture: An Argument With the Future, Londres, Pluto Press, 1994.

Laski, H. J., Reflections on the Revolution of Our Time, London, Allen and Unwin, 1943.

Macpherson, C.B., The Political Theory of Possessive Individualism-Hobbes to Locke, Oxford, Oxford University Press, 1988.

Maff esoli, M., "Introduction to Special Issue on The Imaginary", Current Sociology, Vol. 4I, 2, 1993, pp. 1-45.

Mohanty, C., "Under Western Eyes: Feminist Scholarship and Colonial Discourses", Feminist Review 30, Autumn, 1988, pp. 61-88.

Nun, J., "Democracia y Modernización; Treinta Años Después". Trabajo presentado en la Sesión Plenaria de "Teoría Democrática Hoy: Problemas Teóricos y Empíricos", Asociación Internacional de Ciencia Política, Buenos Aires, julio, 1991.

Payer, C., Lent and Lost-Foreign Credit and Third World Development, Londres, Zed Books, 1991.

Polanyi, K., The Great Transformation-the Political and Economic Origins of Our Time, Boston, Beacon Press, 1957.

Rist, G., “'Development' as Part of the Modern Myth: The Western 'Socio-cultural Dimension' of 'Development', The European Journal of Development Research, Vol. 2, 1, 1990, pp. 10-21.

Verhelst, T.G., No Life Without Roots: Culture and Development, Londres, Zed Press, 1990.

\section{Notas}

1. Docente del Departamento de Sociología y Estudios Sociales de la Universidad de Regina, Saskatchewan, Canadá, y colaborador del Programa de Maestría en Gestión Ambiental de la Universidad Centroamericana "José Simeón Cañas" (UCA).

2. Payer proporciona una serie de ejemplos claros de los efectos de las políticas del FMI/Banco Mundial. Respecto al ajuste estructural, esta autora señala los siguientes cuatro grandes objetivos: (a) la apertura de una economía cerrada o protegida a las fuerzas del mercado mundial a través de la importación o de la liberalización del intercambio; (b) el realineamiento de los precios domésticos a los precios del mercado internacional; (c) la privatización de las empresas estatales; y $(d)$ la reducción de la porción del ingreso nacional destinada a los salarios (1991, p. 96).

3. Esto no significa que la expansión de las inversiones europeas y japonesas no hayan tenido ninguna función en la difusión de la modernización occidental, pero en el contexto de la guerra fría y del establecimiento en los discursos occidentales de identificar el Tercer Mundo como el "otro", Estados Unidos, hoy como ayer, ha mantenido una posición central.

4. En un comentario que aún en estos días conserva su relevancia, Laski indica que en esa época - fines de los años treinta-, a pesar de los arrogantes discursos de los grandes empresarios, en Estados Unidos, el país más rico del mundo, 12 millones de ciudadanos dependían de la caridad para su supervivencia (Laski, 1943, p. 15). 
5. Tomando en cuenta que la máxima: "aquellos que no recuerdan el pasado están condenados a repetirlo" se aplica más a la historia de las ideas que al desenvolvimientọ de los eventos actuales, la subversión y deconstrucción del dogma del "ajuste estructural" y de las nociones presentes del individuo necesitan la relevancia de su contexto histórico. 